\title{
Ketamine added to morphine or hydromorphone patient- controlled analgesia for acute postoperative pain in adults: a systematic review and meta-analysis of randomized trials Addition de kétamine à la morphine ou l'hydromorphone dans l'analgésie contrôlée par le patient pour les douleurs postopératoires aiguës chez l'adulte: revue systématique et méta-analyse des essais randomisés
}

\author{
Li Wang, PhD · Bradley Johnston, PhD · Alka Kaushal, MBBS · Davy Cheng, MD • \\ Fang Zhu, PhD $\cdot$ Janet Martin, PharmD \\ Received: 10 February 2015/Revised: 13 July 2015/Accepted: 19 November 2015/Published online: 10 December 2015 \\ (C) Canadian Anesthesiologists' Society 2015
}

\begin{abstract}
Purpose To determine whether ketamine added to morphine or hydromorphone patient-controlled analgesia (PCA) provides clinically relevant reductions in postoperative pain, opioid requirements, and adverse events when compared with morphine or hydromorphone PCA in adults undergoing surgery.
\end{abstract}

\footnotetext{
Author contributions Li Wang contributed to study conception, drafting the manuscript, and manuscript revisions based on the comments of the coauthors. Li Wang, Bradley Johnston, and Janet Martin contributed to the study design. Li Wang, Alka Kaushal, and Fang Zhu were involved in the acquisition of data. Li Wang contributed to the data analysis. Li Wang, Davy Cheng, and Janet Martin contributed to the interpretation of data. Bradley Johnston participated in statistical analysis. Bradley Johnston, Alka Kaushal, Fang Zhu, Davy Cheng, and Janet Martin were involved in critically revising the manuscript. Davy Cheng and Janet Martin contributed to study supervision.
}

The original version of this abstract was awarded the "2013 Best Paper Award" at the Canadian Anesthesiology Society Annual Meeting, 2013, Calgary, Alberta, Canada. The current version has been updated.

This article is accompanied by an editorial. Please see Can J Anesth 2016; 63: this issue.

Electronic supplementary material The online version of this article (doi:10.1007/s12630-015-0551-4) contains supplementary material, which is available to authorized users.

L. Wang, PhD - D. Cheng, MD · F. Zhu, PhD .

J. Martin, PharmD

Centre for Medical Evidence, Decision Integrity and Clinical

Impact (MEDICI), Western University, London, ON, Canada
Source We systematically searched six databases up to June 2, 2015 for randomized controlled trials (RCTs) comparing ketamine plus morphine/hydromorphone PCA vs morphine/hydromorphone PCA for postoperative pain in adults.

Principal findings Thirty-six RCTs including 2,502 patients proved eligible, and 22 of these were at low risk of bias. The addition of ketamine to morphinel

\section{Wang, PhD}

Michael G. DeGroote Institute for Pain Research and Care,

McMaster University, Hamilton, ON, Canada

L. Wang, PhD

Chinese Cochrane Centre, West China Hospital, Sichuan

University, Chengdu, China

B. Johnston, $\mathrm{PhD}$

Department of Anesthesia and Pain Medicine, and Child Health

Evaluative Sciences, The Hospital for Sick Children, Toronto,

ON, Canada

\section{B. Johnston, $\mathrm{PhD}$}

Institute of Health Policy, Management and Evaluation, Dalla Lana School of Public Health, University of Toronto, Toronto, ON, Canada

\section{A. Kaushal, MBBS}

Department of Clinical Epidemiology and Biostatistics,

McMaster University, Hamilton, ON, Canada

\section{A. Kaushal, MBBS}

Department of Anesthesia and Pain Medicine, The Hospital for Sick Children, Toronto, ON, Canada 
hydromorphone PCA decreased postoperative pain intensity at six to $72 \mathrm{hr}$ when measured at rest (weighted mean difference [WMD] on a 10-cm visual analogue scale ranged from -0.4 to $-1.3 \mathrm{~cm}$ ) and during mobilization (WMD ranged from -0.4 to $-0.5 \mathrm{~cm}$ ). Adjunctive ketamine also significantly reduced cumulative morphine consumption at 24-72 $\mathrm{hr}$ by approximately 5-20 $\mathrm{mg}$. Predefined subgroup analyses and meta-regression did not detect significant differences across subgroups, including a dose-response relationship. There was no significant difference in patient satisfaction scores at 24 and $48 \mathrm{hr}$. Nevertheless, the addition of ketamine to morphine/hydromorphone PCA significantly reduced postoperative nausea and vomiting (relative risk, 0.71; 95\% confidence interval [CI], 0.60 to 0.85; absolute risk reduction, 8.9\%; 95\% CI, 4.6 to 12.2). Significant effects on other adverse events (e.g., hallucinations, vivid dreams) were not detected, though only a few studies reported on them.

Conclusions Adding ketamine to morphine/ hydromorphone PCA provides a small improvement in postoperative analgesia while reducing opioid requirements. Adjunctive ketamine also reduces postoperative nausea and vomiting without a detected increase in other adverse effects; however, adverse events were probably underreported.

\section{Résumé}

Objectif Déterminer si l'addition de kétamine à la morphine ou l'hydromorphone dans l'analgésie contrôlée par le patient $(A C P)$ entraîne des réductions cliniquement pertinentes des douleurs postopératoires, des besoins en opioüdes et des événements indésirables comparativement à la ACP par morphine ou hydromorphone chez des adultes subissant une intervention chirurgicale.

Source Nous avons procédé à une recherche systématique dans six bases de données jusqu'au 2 juin 2015 pour identifier les essais cliniques randomisés comparant la ACP par kétamine plus morphine/hydromorphone à l'ACP

D. Cheng, MD $\cdot$ J. Martin, PharmD

Department of Anesthesia \& Perioperative Medicine, Western University, London, ON, Canada

J. Martin, PharmD

Department of Epidemiology \& Biostatistics, Western University, London, ON, Canada

J. Martin, PharmD ( $\square)$

Centre for Medical Evidence, Decision Integrity and Clinical Impact (MEDICI), and Department of Anesthesia \& Perioperative Medicine, Schulich School of Medicine \& Dentistry, Western University, Room B3-412, 339 Windermere Road, London, ON N6A 5A5, Canada

e-mail: jmarti83@uwo.ca par morphine/hydromorphone pour les douleurs pos topératoires chez les adultes.

Constatations principales Trente-six essais cliniques randomisés ayant inclus 2502 patients ont été retenus, parmi lesquels 22 ont été jugés comme présentant un faible risque de biais. L'ajout de kétamine à une ACP par morphine ou hydromorphone a diminué l'intensité des douleurs postopératoires à 6 à 72 heures, quand elles étaient évaluées au repos (différence moyenne pondérée [WMD] sur une échelle visuelle analogique de $10 \mathrm{~cm}$ allant de 0,4 à $-1,3 \mathrm{~cm}$ ) et pendant la mobilisation (WMD allant de $-0,4$ à $-0,5 \mathrm{~cm}$ ). L'ajout de kétamine a également significativement diminué la consommation cumulée de morphine à 24-72 $h$ d'environ 5 à $20 \mathrm{mg}$. Les analyses prédéfinies de sous-groupes et une métarégression n'ont pas détecté de différences significatives entre les sousgroupes, y compris dans le rapport dose-effet. Il n'y a pas eu de différence significative en matière de satisfaction des patients à 24 h et 48 h. Néanmoins, l'ajout de kétamine à l'ACP par morphine/hydromorphone a réduit significativement les nausées et vomissements postopératoires (risque relatif, 0,71; intervalle de confiance à $95 \%$ [IC] : 0,60 à 0,85 ; réduction du risque absolu, 8,9\%; IC à $95 \%, 4,6$ à 12,2). Des effets significatifs sur d'autres évènements indésirables (hallucinations, rêves d'apparence réelle, par exemple) n'ont pas été détectés bien que peu d'études les aient décrits.

Conclusions L'addition de kétamine à l'ACP par morphine ou hydromorphone procure une petite amélioration de l'analgésie postopératoire tout en réduisant les besoins en opioüdes. L'addition de kétamine a également diminué les nausées et vomissements postopératoires sans détection d'une augmentation des autres évènements indésirables; toutefois, les évènements indésirables ont été probablement sous-déclarés.

Patient-controlled analgesia with opioids is commonly used for treatment and prevention of pain in the perioperative setting. Nevertheless, analgesic success is often limited by opioid-related adverse events, including postoperative nausea and vomiting (PONV), sedation, respiratory depression, ileus, urinary retention, and pruritus. Ketamine, an antagonist of the N-methyl-Daspartate (NMDA) receptor and an inexpensive and potentially opioid-sparing drug, is of increasing interest in pain management, especially in subanesthetic doses. Concurrent treatment with ketamine has been purported to produce comparable or synergistic analgesia while potentially reducing the risk of opioid-related adverse 
effects. In addition, given its mechanism of action within the pathophysiology of pain as a NMDA antagonist centrally and peripherally, it has been suggested that ketamine might provide advantages for reducing the risk of progressing to chronic pain, though this claim awaits definitive clinical trials. ${ }^{1}$ Nevertheless, ketamine also brings dose-related disadvantages, including neuropsychiatric effects (e.g., hallucinations, vivid dreams, and nightmares), cardiovascular adverse effects (e.g., hypertension, tachycardia), and other adverse events (e.g., nausea, dizziness, and blurred vision). Furthermore, the dose required for adequate analgesia remains unclear.

Previously published systematic reviews ${ }^{2-6}$ of ketamine for acute postoperative pain did not include the most recent randomized trials, did not limit studies to a combination of ketamine and morphine or hydromorphone for patients receiving patient-controlled analgesia (PCA), ${ }^{2,4}$ neglected to provide transparent effect sizes or clinically relevant measures of analgesia, and/or generally failed to address important subgroups of interest to our clinical practice. ${ }^{2,3,6}$ For the above reasons, we performed a de novo comprehensive systematic review and meta-analysis of randomized trials to address the following question adequately: Does ketamine added to morphine or hydromorphone PCA provide clinically relevant reductions in postoperative pain, opioid requirements, and opioid-related adverse events without undue risk of neuropsychiatric effects when compared with morphine or hydromorphone PCA in adults undergoing surgery?

\section{Methods}

The systematic review was conducted according to a protocol that predefined the inclusion criteria, relevant outcomes, and analysis plan and was reported in accordance with the PRISMA Statement. ${ }^{7}$ Post hoc amendments to the protocol included the addition of hydromorphone PCA to our originally planned metaanalysis of morphine only PCA. We introduced this change to increase the generalizability of the results. Submission to an ethics review board was not required for approval of this meta-analysis.

\section{Data sources and searching}

In collaboration with medical librarians, we performed systematic searches-from inception to June 2, 2015-of six databases, including PubMed, EMBASE ${ }^{\mathrm{TM}}$, Cochrane Central Register of Controlled Trials (CENTRAL), and three Chinese databases, including Chinese Biomedical Literature Database (CBM), China National Knowledge Infrastructure (CNKI), and Wanfang Data.
Search terms included both MeSH headings and free text for "ketamine", "patient controlled analgesia", "postoperative", "surgery", "pain", and "randomized controlled trials" (Search strategies in the Appendix, available as Electronic Supplementary Material). No limits were placed on language, type of surgery, and mode of ketamine administration. Bibliographies of relevant systematic reviews and included studies were manually checked to identify potentially relevant studies.

\section{Study selection}

To be eligible for inclusion, the studies had to be randomized controlled trials (RCTs) with parallel group designs comparing the combination of ketamine plus morphine or hydromorphone in PCA vs morphine/ hydromorphone PCA for acute postoperative pain in adults. Only studies using subanesthetic doses of ketamine were included, defined as a bolus dose of $\leq 2$ $\mathrm{mg} \cdot \mathrm{kg}^{-1}$ when given intramuscularly, or $\leq 1 \mathrm{mg} \cdot \mathrm{kg}^{-1}$ when administered via intravenous or epidural route, or an intravenous infusion rate of $\leq 20 \mu \mathrm{g} \cdot \mathrm{kg}^{-1} \cdot \mathrm{min}^{-18}$. The primary outcome measures of interest were acute pain scores at rest and during mobilization. Secondary outcome measures included cumulative morphine consumption (after converting hydromorphone and/or other supplemental opioids to the morphine equivalent dose), patient satisfaction, total rescue narcotics, PONV, and other adverse events (e.g., respiratory depression, drowsiness, pruritus, dizziness, hallucinations, vivid dreams or nightmares, and cardiovascular adverse effects such as hypertension and tachycardia).

Two reviewers screened citations independently and retrieved the full text of any article deemed potentially eligible. Subsequently, two pairs of reviewers independently assessed the eligibility of each full-text article (L.W. \& A.K., or L.W. \& F.Z.). Reviewers resolved discrepancies by discussion and, when necessary, through arbitration by a third reviewer (J.M. or D.C.).

\section{Data extraction}

Using standardized piloted forms, two reviewers independently extracted data on patient characteristics (mean age, sex, American Society of Anesthesiologists physical status, types and mean duration of surgery), interventions (ratio of ketamine-to-morphine, route, timing, dose, duration of ketamine and morphine, total dose of ketamine, maximum length of follow-up, type of anesthesia, postoperative analgesia, rescue analgesia, and nitrous oxide), and all relevant clinical outcomes.

We extracted pain intensity scores and cumulative morphine consumption for the following time points: four 
to six hours, ten to $12 \mathrm{hr}, 24 \mathrm{hr}, 48 \mathrm{hr}$, and $72 \mathrm{hr}$ postoperatively. All other outcomes were extracted for the last reported time point. When the article did not report whether the pain score was measured at rest or during mobilization, we assumed it was at rest. When authors reported measuring pain at rest and during movement but neglected to differentiate the two in their study results, we assumed the pain score was collected during mobilization. Subsequently, we conducted a sensitivity analysis to address the robustness of these assumptions by using only the data in which the designation of pain was unequivocally either at rest or during movement.

\section{Risk of bias assessment}

Two reviewers independently assessed the risk of bias of the included trials using the methods recommended by the Cochrane Collaboration, ${ }^{9}$ including random sequence generation, allocation concealment, missing or incomplete outcome data, and blinding of patients, study personnel, and outcome assessors.

\section{Data analysis}

When standard deviations (SDs) were not reported directly, we estimated the SD from standard errors, confidence intervals, Student's $t$ values, and $P$ values using the methods recommended in the recent Cochrane Handbook. ${ }^{9}$ When the articles reported the median with interquartile range, range, or $P$ value, we assumed that the distribution of data was normal and estimated the mean and SD. If the article reported the data using a frequency table, we calculated the mean and SD. If authors presented continuous data in figures, we measured the mean and standard deviation from the figures. Sensitivity analysis was performed by excluding the estimated mean and SD to explore if these methods of imputing mean and SD had an impact on the overall effect size. If a study reported both nausea and vomiting separately, we chose the largest number of events to estimate the PONV. Sensitivity analysis was applied by excluding the estimated PONV.

Weighted mean difference (WMD) and 95\% confidence interval (CI) were calculated for continuous data, and relative risk (RR) and 95\% CI were calculated for binary data using the random effects model. Risk differences (RD) were also presented for binary data, including all adverse events. When scores for pain and patient satisfaction were reported on a $100-\mathrm{mm}$ visual analogue scale (VAS), a fivepoint verbal rating scale, or other scales, they were converted to a $10-\mathrm{cm} \mathrm{VAS} .^{10}$

Both the Chi square test and $\mathrm{I}^{2}$ were used to estimate the heterogeneity across trials. If $P<0.10$ or $\mathrm{I}^{2}>50 \%$, we used subgroup analyses or meta-regression (for variables with more than two categories) to detect potential sources of heterogeneity. Post hoc subgroup analyses included different types of opioid (morphine PCA vs hydromorphone PCA, with postulated larger effects with hydromorphone PCA) for the outcomes of pain on VAS, cumulative opioid consumption in morphine equivalents, patient satisfaction, and PONV. When heterogeneity was found for the primary outcome (i.e., pain) and was not explained by type of opioid PCA, predefined subgroup analyses were performed for type of surgery (postulated larger effects for cardiac or thoracic surgeries), mode (postulated larger effect with ketamine in PCA $v s$ infusion), duration of ketamine administered (postulated longer duration would lead to larger effects), use of nitrous oxide (larger effects when nitrous oxide is coadministered) and other postoperative analgesics (larger effects with other analgesic coadministration), risk of bias (larger effects for high risk of bias studies), and language of publication (larger effects in non-English studies). Metaregression was performed to evaluate the ketamine doseresponse relationship and the association of the ratio of ketamine-to-morphine with the effect estimates of postoperative pain. For subgroup analysis, the test for interaction was used to evaluate whether effect sizes differed significantly across subgroups. This test is recommended $^{9}$ rather than relying on the blunt test of significance where each subgroup is considered separately to detect whether each reached $P<0.05$. For metaregression, the $P$ value for the slope was calculated. All reported $P$ values are two sided.

Both visual inspection of funnel plots and Egger's test were used to explore publication bias for pain and morphine consumption at $24 \mathrm{hr}$ and $48 \mathrm{hr}$, PONV, and hallucinations.

We used GRADE to summarize confidence in estimates of effect (quality of evidence) in the critically important outcomes for decision-making, including pain scores at 24 hr and $48 \mathrm{hr}$, PONV, and the risk of other adverse events (e.g., hallucination and vivid dreams). ${ }^{11-17}$

\section{Results}

The search identified 801 articles, of which we included 36 RCTs, 31 published in English ${ }^{18-48}$ and five in Chinese ${ }^{49-53}$ (Fig. 1).

Characteristics of included studies

Supplementary Table 1 (available as Electronic Supplementary Material) illustrates the characteristics of the included studies. Thirty-three trials ${ }^{18-45,49-53}$ comprising 2,374 patients compared ketamine plus 


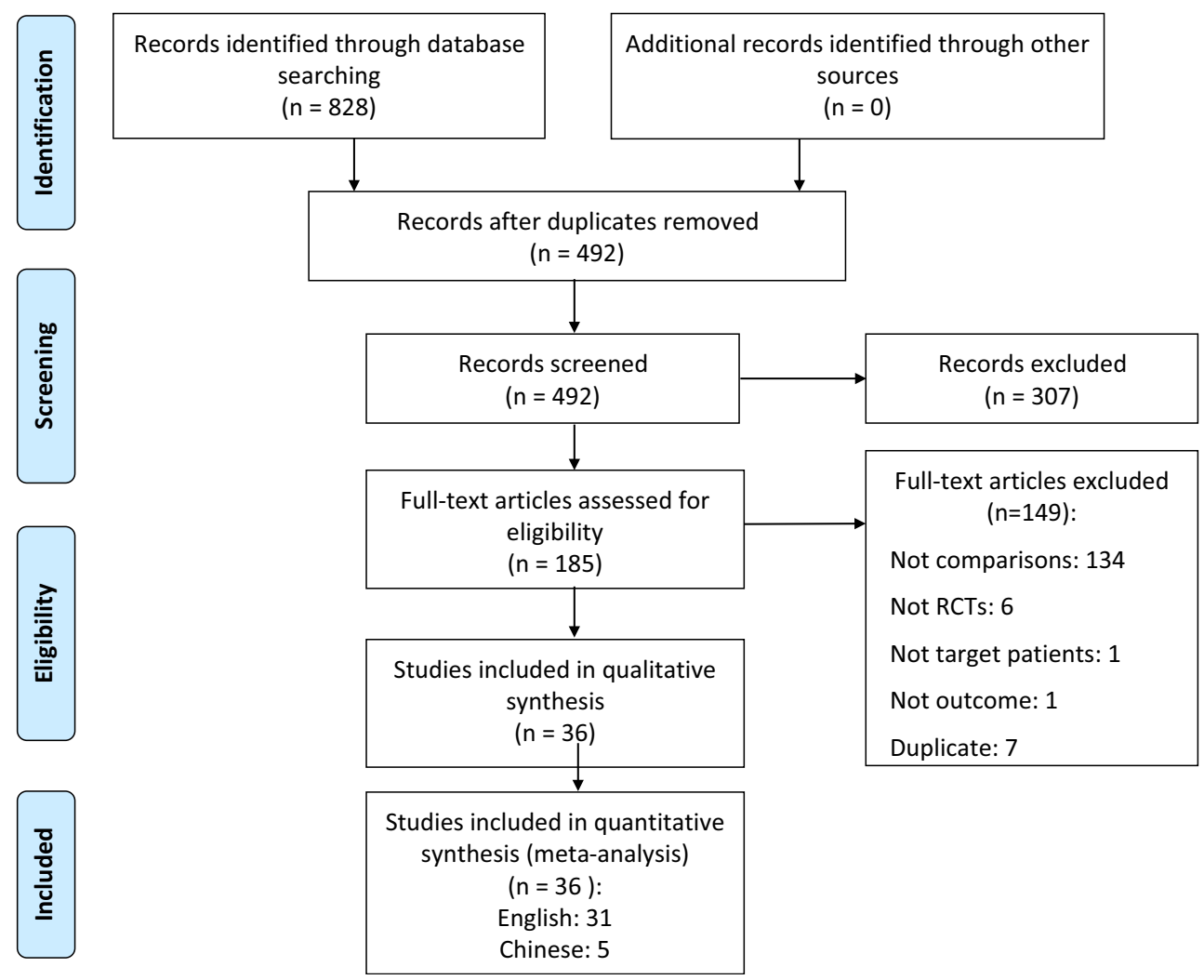

Fig. 1 Combination of ketamine and morphine/hydromorphone patient-controlled analgesia (PCA) vs morphine/hydromorphone PCA: flow diagram of study selection

morphine PCA in 37 treatment arms with morphine PCA in 33 control arms. Three trials involving 128 patients ${ }^{46-48}$ compared ketamine plus hydromorphone PCA with hydromorphone PCA. Patients underwent a variety of surgeries: abdominal surgery (17 trials), ${ }^{18,20-22,25-27,29,30,32,34,36,40,41,44,45,50}$ cardiac or thoracic surgery (six trials), ${ }^{19,23,35,37,38,53}$ orthopedic surgery (ten trials), ${ }^{24,28,31,33,39,43,47-49,51}$ and other surgery (three trials). ${ }^{42,46,52}$ General anesthesia was used in 34 trials; one trial used PCA during and after a uterine artery embolization procedure, ${ }^{29}$ and one used either general or regional anesthesia. ${ }^{43}$ The target patients in one study were male opium abusers undergoing orthopedic surgery with morphine PCA for postoperative pain control, ${ }^{24}$ and in another three studies, patients with chronic pain were managed with opioids preoperatively and with hydromorphone PCA for postoperative pain control. ${ }^{46-48}$

Ketamine was administered via PCA in 26 trials, with a ketamine:morphine ratio of $1: 1 \quad$ (13 trials), ${ }^{19,27-30,32,35,39-41,43,49,51} 5: 1$ (four trials), ${ }^{23,31,37,38} 2.5: 1$ (one trial), ${ }^{44} 2: 1$ (four trials), ${ }^{22,24,51,53} 0.75: 1$ (one trial), ${ }^{36} 0.5: 1$ (three trials), ${ }^{20,42,52}$ and 0.04 or $0.07: 1$ (one trial). ${ }^{50}$ Ketamine was administered by infusion in 11 trials. $^{18,22,25,26,30,33,34,38,39,45-48,51,52}$ Ketamine was given peri operatively in 11 trials $^{20,21,27,33,34,39,42,45,47,48,52}$ and postopera tively in 25 trials. $^{18,19,22-26,28-32,35-38,40,41,43,44,46,49-51,53}$ Ten trials stated that acetaminophen, ${ }^{19,25,27,29,35,41,43,45}$ midazolam, $^{30}$ and epidural bupivacaine ${ }^{47}$ were used for postoperative analgesia besides morphine or hydromorphone PCA. Also, intraoperative nitrous oxide was used in 18 trials. ${ }^{18,26-28,32,35,38-45,48,50-52}$ The duration of follow-up ranged from four to $100 \mathrm{hr}$ postoperatively (Supplementary Table 1).

\section{Risk of bias}

Among 36 trials, adequate sequence generation was repo rted in 23 trials, ${ }^{20-25,29,31-35,37-39,41-43,45-48,50 ~ a l l o c a t i o n ~}$ concealment in 21 trials, ${ }^{20-23,25,27,29-35,38,39,42,43,45-48}$ blinding in 31 trials, $^{18,20-23,25-48,50,53}$ and incomplete

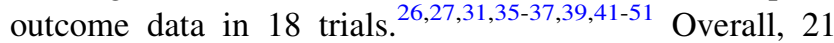
out of 36 included trials were rated as low risk of bias, ${ }^{20-23,25,27,29-35,37,38,41-43,45,46,48}$ and 15 trials were rated as high risk of bias ${ }^{18,19,24,26,28,36,39,40,44,47,49-53}$ (Supple mentary Table 2).

Primary outcome measure: pain intensity

As shown in Tables 1 and 2, the reduction in VAS score in the ketamine plus morphine or hydromorphone PCA group was 
Table 1 Summary of results for combination of ketamine plus morphine/hydromorphone PCA $v s$ morphine/hydromorphone PCA

\begin{tabular}{|c|c|c|c|c|c|c|c|}
\hline Outcomes & $\begin{array}{l}\text { Time } \\
\text { point }\end{array}$ & $\begin{array}{l}\text { No. of } \\
\text { comparisons }\end{array}$ & $\begin{array}{l}\text { Sample } \\
\text { size }\end{array}$ & $\begin{array}{l}\text { Heterogeneity } P \\
\text { value }\end{array}$ & $\begin{array}{l}\mathrm{I}^{2} \\
(\%)\end{array}$ & WMD $(95 \% \mathrm{CI})$ & $\mathrm{RR}(95 \% \mathrm{CI})$ \\
\hline \multirow[t]{5}{*}{ Pain score at rest } & $4-6 \mathrm{hr}$ & 25 & 1,406 & $<0.001$ & 87 & $-0.9(-1.2$ to -0.5$)$ & - \\
\hline & $12 \mathrm{hr}$ & 20 & 1,093 & $<0.001$ & 89 & $-0.8(-1.2$ to -0.4$)$ & - \\
\hline & $24 \mathrm{hr}$ & 33 & 1,888 & $<0.001$ & 89 & $-0.6(-0.8$ to -0.3$)$ & - \\
\hline & $48 \mathrm{hr}$ & 24 & 1,746 & $<0.001$ & 85 & $-0.4(-0.6$ to -0.2$)$ & - \\
\hline & $72 \mathrm{hr}$ & 4 & 215 & $<0.001$ & 89 & $-1.3(-2.4$ to -0.2$)$ & - \\
\hline \multirow[t]{4}{*}{ Pain score during mobilization } & $4-6 \mathrm{hr}$ & 7 & 750 & $<0.001$ & 89 & $-0.1(-0.9$ to +0.7$)$ & - \\
\hline & $12 \mathrm{hr}$ & 9 & 824 & 0.08 & 43 & $-0.5(-0.8$ to -0.2$)$ & - \\
\hline & $24 \mathrm{hr}$ & 15 & 1,144 & 0.18 & 25 & $-0.4(-0.6$ to -0.2$)$ & - \\
\hline & $48 \mathrm{hr}$ & 12 & 1,055 & 0.07 & 41 & $-0.5(-0.8$ to -0.2$)$ & - \\
\hline \multirow[t]{3}{*}{ Cumulative morphine consumption } & $24 \mathrm{hr}$ & 30 & 1,882 & $<0.001$ & 82 & $-5.0(-7.2$ to -2.8$)$ & - \\
\hline & $48 \mathrm{hr}$ & 22 & 1,196 & $<0.001$ & 83 & $-12.7(-18.9$ to -6.6$)$ & - \\
\hline & $72 \mathrm{hr}$ & 5 & 533 & 0.791 & 0 & $-20.2(-27.7$ to -12.7$)$ & - \\
\hline \multirow[t]{2}{*}{ Patient satisfaction scores } & $24 \mathrm{hr}$ & 6 & 353 & 0.02 & 61 & $0.05(-0.5$ to 0.6$)$ & - \\
\hline & $48 \mathrm{hr}$ & 4 & 217 & 0.03 & 67 & $0.02(-1.1$ to 1.1$)$ & - \\
\hline Rescue analgesia requirement & & 14 & 1,069 & 0.13 & 31 & - & $0.76(0.56$ to 1.05$)$ \\
\hline Postoperative nausea and vomiting & & 30 & 2,143 & 0.03 & 35 & - & $0.71(0.60$ to 0.85$)$ \\
\hline Hallucination & & 22 & 1,488 & 0.88 & 0 & - & $1.27(0.81$ to 1.98$)$ \\
\hline Vivid dreams & & 14 & 734 & 0.96 & 0 & - & $1.21(0.77$ to 1.90$)$ \\
\hline Dysphoria & & 15 & 882 & 0.56 & 0 & - & $1.00(0.55$ to 1.84$)$ \\
\hline Pruritus & & 15 & 1,287 & 0.41 & 3 & - & $0.92(0.69$ to 1.22$)$ \\
\hline Respiratory depression & & 12 & 1,030 & 0.06 & 45 & - & $0.59(0.30$ to 1.17$)$ \\
\hline Urinary retention & & 8 & 549 & 0.86 & 0 & - & $0.76(0.53$ to 1.09$)$ \\
\hline Diplopia & & 3 & 260 & 0.69 & 0 & - & $1.53(0.59,3.96)$ \\
\hline Cardiovascular adverse effects\# & & 2 & 120 & 0.20 & 39 & - & $1.51(0.14,16.28)$ \\
\hline
\end{tabular}

$\mathrm{CI}=$ confidence interval; $\mathrm{PCA}=$ patient-controlled analgesia; $\mathrm{RD}=$ risk difference; $\mathrm{RR}=$ relative risk; $\mathrm{WMD}=$ weighted mean difference

\# Cardiovascular adverse effects included arrhythmia, hypotension, hypertension, and bradycardia

low but statistically significant compared with the morphine or hydromorphone PCA group at every time point examined (i.e., six, 12, 24, 48, and $72 \mathrm{hr}$ ) postoperatively. The reduction of pain at rest ranged from $0.6 \mathrm{~cm}(95 \% \mathrm{CI}, 0.3$ to 0.8$)$ at $24 \mathrm{hr}$ to $1.3 \mathrm{~cm}(95 \% \mathrm{CI}, 0.2$ to 2.4$)$ at $72 \mathrm{hr}$; and reduction of pain during mobilization ranged from $0.4 \mathrm{~cm}(95 \% \mathrm{CI}, 0.2$ to 0.6$)$ at $24 \mathrm{hr}$ to $0.5 \mathrm{~cm}(95 \% \mathrm{CI}, 0.2$ to 0.8$)$ at $48 \mathrm{hr}$ (Figs. 2 \& 3, Supplementary Figs. $1 \& 2$, and Table 1). The GRADE ratings of confidence in estimates varied from moderate to high (Table 2).

Secondary outcome measures

\section{Cumulative morphine consumption and rescue analgesia}

The addition of ketamine to PCA reduced cumulative morphine consumption compared with morphine or hydromorphone PCA after converting total opioid consumption to morphine equivalents. Reductions in total morphine consumption ranged from $5.0 \mathrm{mg}$ (95\% CI, 2.8 to 7.2) at $24 \mathrm{hr}$ to $20.2 \mathrm{mg}$ (95\% CI, 12.7 to 27.7$)$ at $72 \mathrm{hr}$ (Table 1, Fig. 4, and Supplementary Fig. 3).

Numerically fewer patients using ketamine plus morphine/hydromorphone PCA required rescue analgesia, but significant differences were not found (14 trials; 1,069 patients; RR, 0.76 ; $95 \%$ CI, 0.56 to 1.05 ) (Table 1).

Patient satisfaction

Seven trials of 383 patients reported patient satisfaction scores using different instruments (five trials used $10-\mathrm{cm}$ VAS for satisfaction, ${ }^{22,23,27,46,47}$ one used a five-point verbal rating scale for satisfaction, ${ }^{40}$ and one used a numeric rating scale (NRS) of 0-10 for discomfort. ${ }^{44}$ After converting the results to the same direction (higher score indicates more satisfied) and the same scale (10-cm VAS), no significant difference was detected for patient satisfaction scores at 24 hours (six trials; 353 patients; WMD, $0.05 ; 95 \% \mathrm{CI},-0.5$ to 


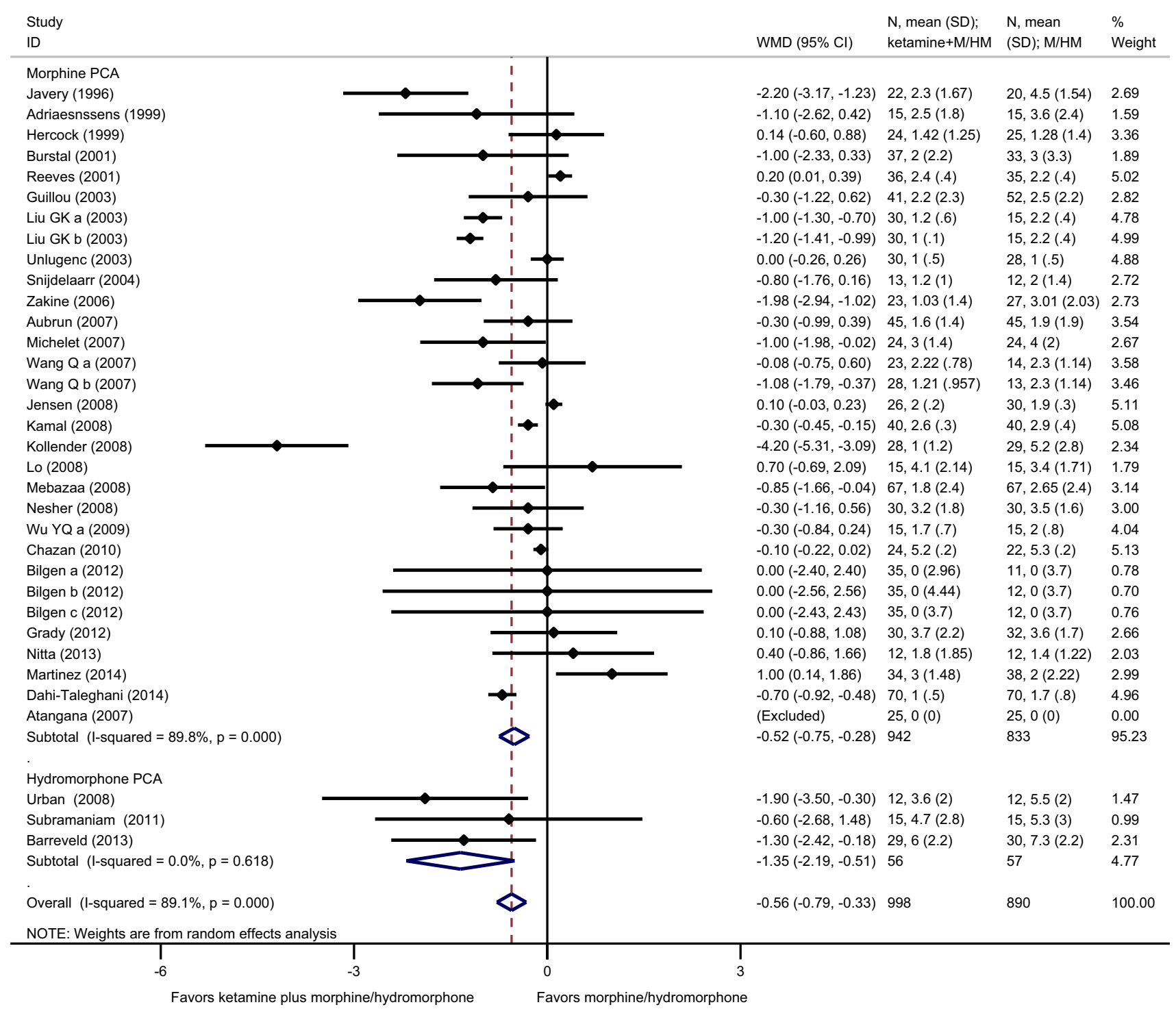

Fig. 2 Combination of ketamine and morphine/hydromorphone patient-controlled analgesia (PCA) vs morphine/hydromorphone PCA: 24-hr pain score at rest on a $0-10$ scale

0.6) and at $48 \mathrm{hr}$ postoperatively (four trials; 217 patients; WMD, $0.02 ; 95 \% \mathrm{CI},-1.1$ to 1.1 ) (Table 1 ).

Postoperative nausea and vomiting

Ketamine added to morphine/hydromorphone significantly reduced PONV in 30 trials involving 2,143 patients (RR, $0.71 ; 95 \% \mathrm{CI}, 0.60$ to 0.85 ; RD, $-8.9 \% ; 95 \% \mathrm{CI},-4.6$ to -12.2) (Tables 1 \& 2, Fig. 5) (GRADE: moderate confidence in estimates, Table 2).

Other adverse events

No significant differences were found for other adverse events, including hallucinations (22 trials; 70 events; 1,488 patients; RR, 1.27 ; $95 \% \mathrm{CI}, 0.81$ to 1.98 ; RD, $0.9 \%$; $95 \% \mathrm{CI}$, -0.6 to 3.1 ) (GRADE: moderate confidence in estimates, Table 2), vivid dreams (14 trials; 62 events; 734 patients; RR, $1.21 ; 95 \% \mathrm{CI}, 0.77$ to $1.90 ; \mathrm{RD}, 2.3 \%$; $95 \% \mathrm{CI},-2.5$ to 9.9 ) (GRADE: moderate confidence in estimates, Table 2), dysphoria (15 trials; 42 events; 882 patients; RR, 1.00; 95\% CI, 0.55 to 1.84 ), pruritus ( 15 trials; 185 events; 1,287 patients; RR, $0.92 ; 95 \% \mathrm{CI}, 0.69$ to 1.22 ), respiratory depression (12 trials; 87 events; 1,030 patients; RR, 0.59; 95\% CI, 0.30 to 1.17), urinary retention (eight trials; 86 events; 549 patients; RR, 0.76; 95\% CI, 0.53 to 1.09), and diplopia (three trials; 18 events; 260 patients; RR, 1.53 ; 95\% CI, 0.59 to 3.96), and cardiovascular adverse effects, including arrhythmia, hypotension, hypertension, or bradycardia (two trials; six events; 120 patients; RR, 1.51 ; $95 \%$ CI, 0.14 to 16.28 ). 


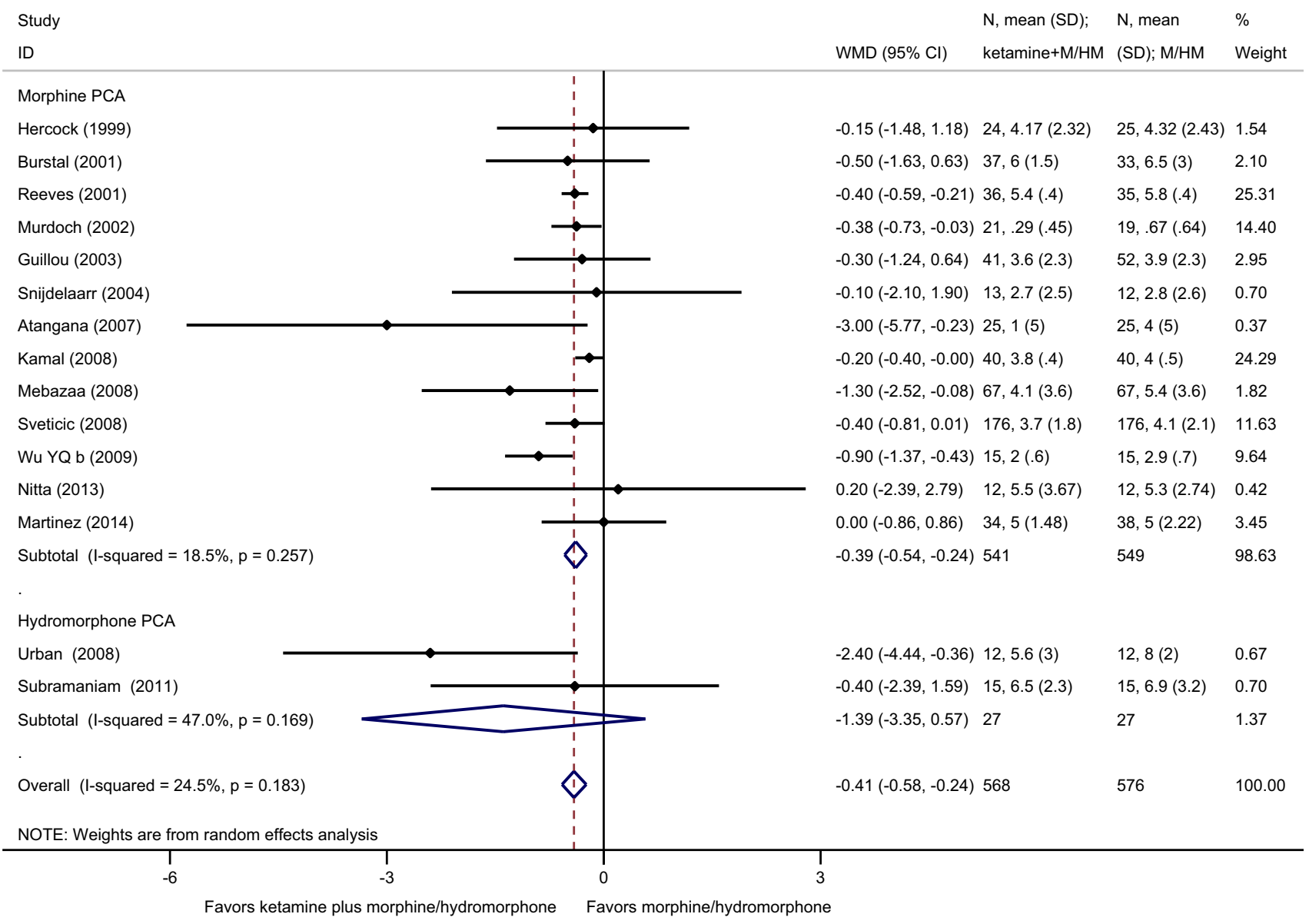

Fig. 3 Combination of ketamine and morphine/hydromorphone patient-controlled analgesia (PCA) vs morphine/hydromorphone PCA: 24-hr pain score during mobilization on a $0-10$ scale

Subgroup analyses and sensitivity analyses

Meta-regression did not detect a significant dose relationship between ketamine doses and pain scores $(P$ value ranged from 0.44 to 0.92 ). Also, meta-regression did not detect a significant association between the ratio of ketamine-to-morphine and pain scores $(P$ value ranged from 0.08 to 0.35 ).

No significant subgroup effects were detected between morphine PCA and hydromorphone PCA for pain at rest and movement, total opioid consumption (in morphine equivalent), patient satisfaction, and PONV (interaction $P$ value ranged from 0.10 to 0.93 ) (Table 3 ); however, only three of the 36 included studies evaluated ketamine plus hydromorphone PCA.

In addition, other predefined subgroup analyses did not find significant interactions between pain and different subgroups, including type of surgery, mode and duration of ketamine administered, use of nitrous oxide and other postoperative analgesics, risk of bias, and language of publication (interaction $P$ value ranged from 0.11 to 0.98 ) (Supplementary Table 3).

Sensitivity analyses suggested that the effects of pain intensity and cumulative morphine consumption were robust across our approaches to imputing data for missing means and SDs and across our assumptions about pain score measured at rest or mobilization. Nevertheless, the confidence interval using the clearly reported data of mean and SD or pain scores at rest and mobilization was wider due to the smaller sample size (Supplementary Table 4). Also, the result was robust after removing the imputed PONV from the largest number of events of nausea and vomiting.

Publication bias

Publication bias was not detected for any outcomes (Supplementary Figs. 4, 5, 6) with the exception of PONV (Egger's test $P=0.001$ ). 


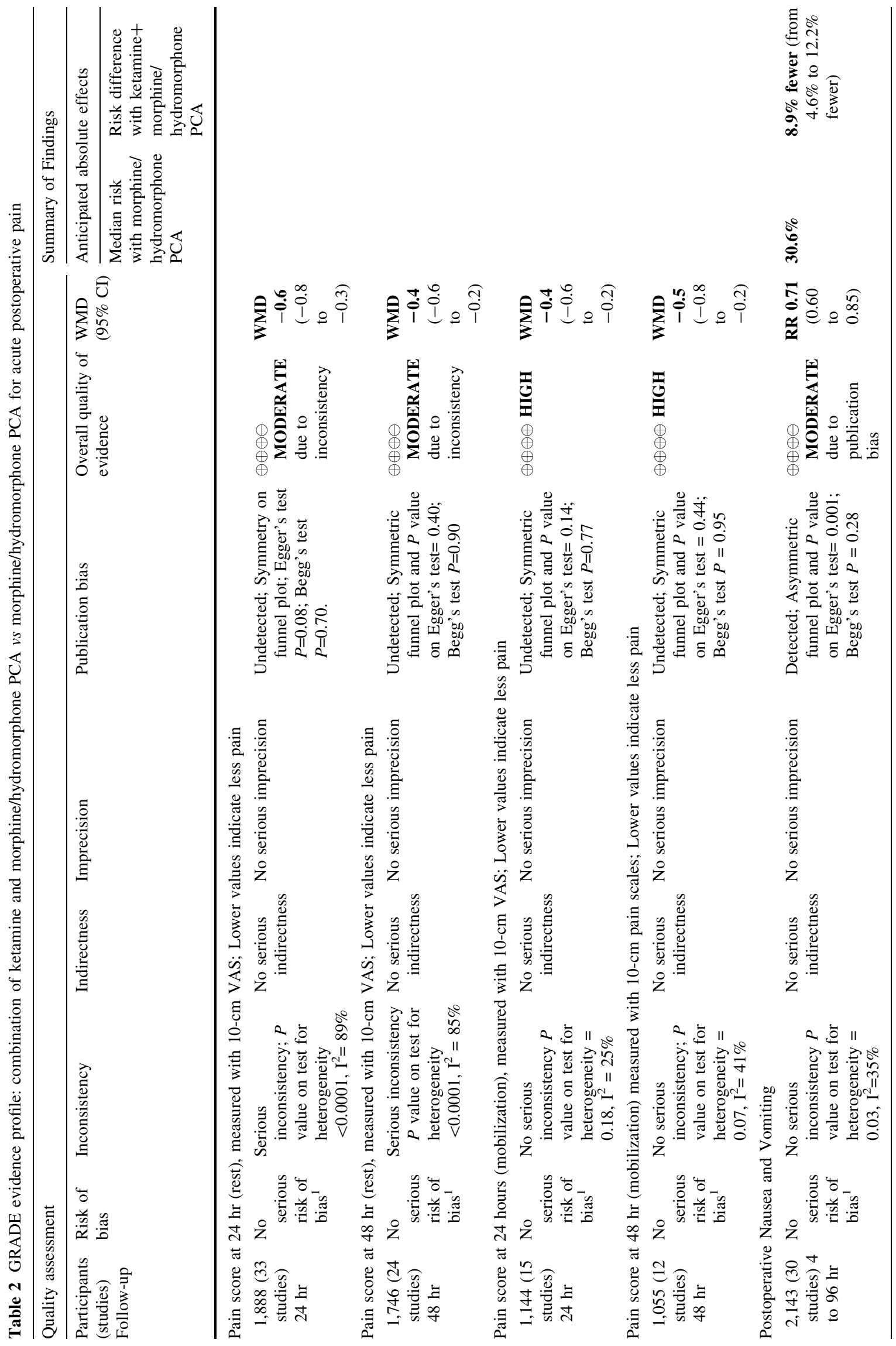




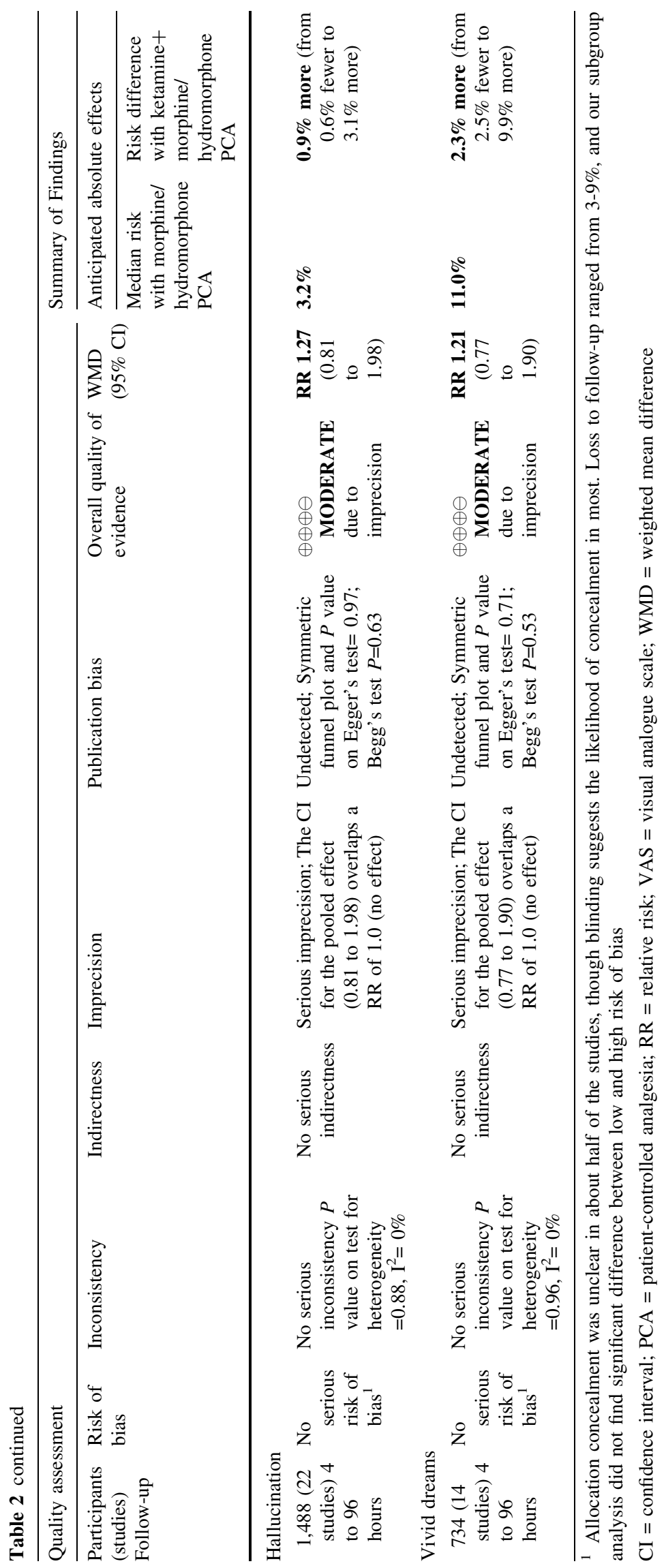




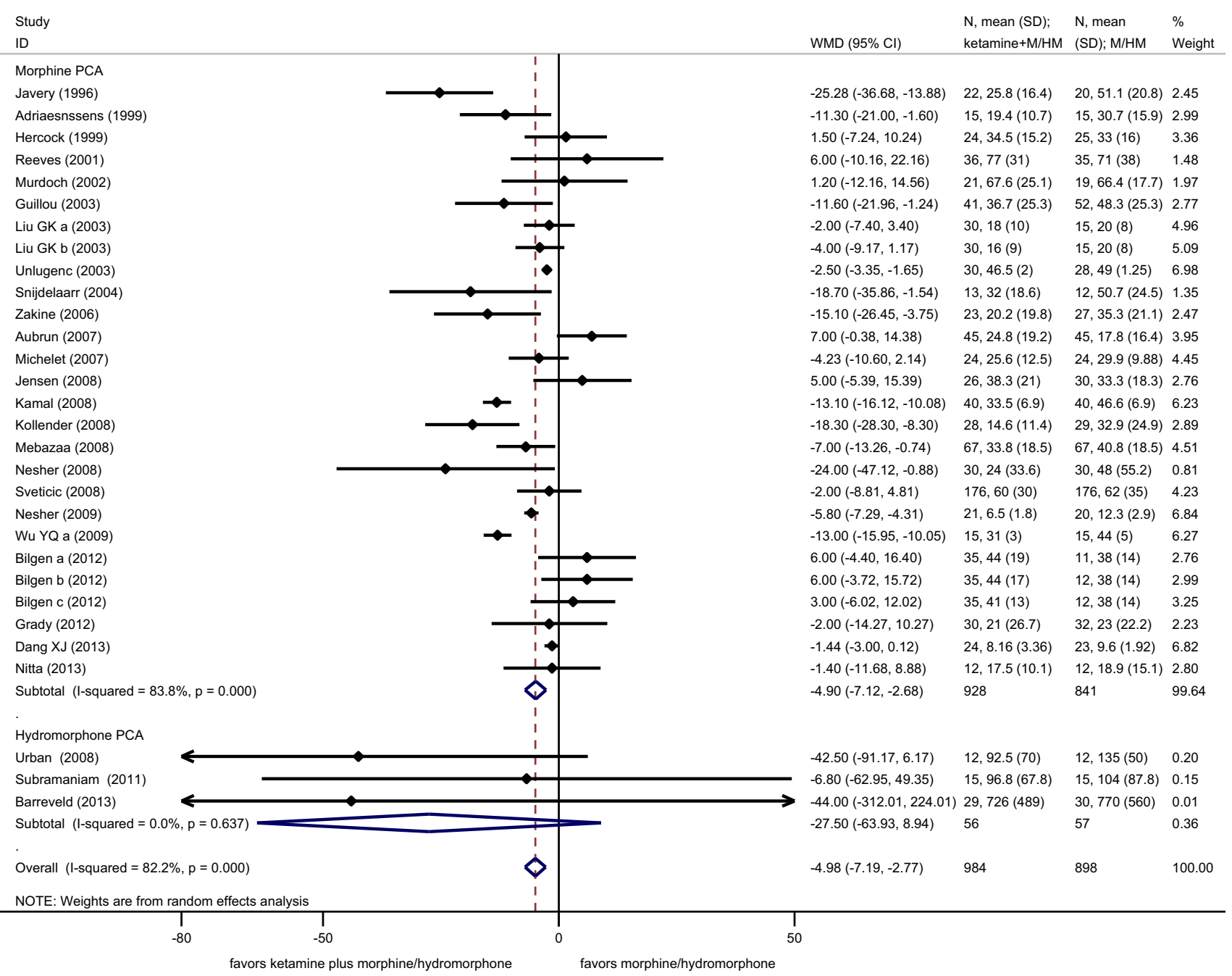

Fig. 4 Combination of ketamine and morphine/hydromorphone patient-controlled analgesia (PCA) vs morphine/hydromorphone PCA: 24-hr cumulative morphine consumption $(\mathrm{mg})$

\section{Discussion}

\section{Main findings}

Ketamine added to morphine or hydromorphone PCA resulted in small reductions $(<1 \mathrm{~cm}$ pain reduction on a $10-\mathrm{cm}$ VAS) in postoperative pain compared with morphine or hydromorphone PCA. These reductions were achieved despite lower morphine requirements for those receiving ketamine (reductions in cumulative morphine consumption during postoperative day 1 or day 3 of 5-20 $\mathrm{mg})$.

\section{Relationship with prior reviews}

This meta-analysis adds significantly to previous systematic reviews of ketamine for acute postoperative pain since we found a number of new studies not previously incorporated. In addition, this meta-analysis quantifies the reduction of postoperative pain, cumulative morphine consumption, and PONV, which advances knowledge compared with the qualitative systematic review of 11 trials $(n=887)$ on the same topic. ${ }^{3}$ While our findings are consistent with two previous systematic reviews regarding a reduction of total opioid consumption and PONV, it is important to point out that both prior reviews compared ketamine given at any point (preemptively, intraoperatively, postoperatively) and administered by any routes (intravenous, intramuscular, or epidural administration) or by any method of intravenous administration (bolus, infusion, PCA), and they did not specifically address the addition of ketamine to morphine or hydromorphone PCA. ${ }^{2,5}$ There are two older systematic reviews that did address the addition of ketamine to morphine PCA, but they included only a small proportion of the studies available today and did not 


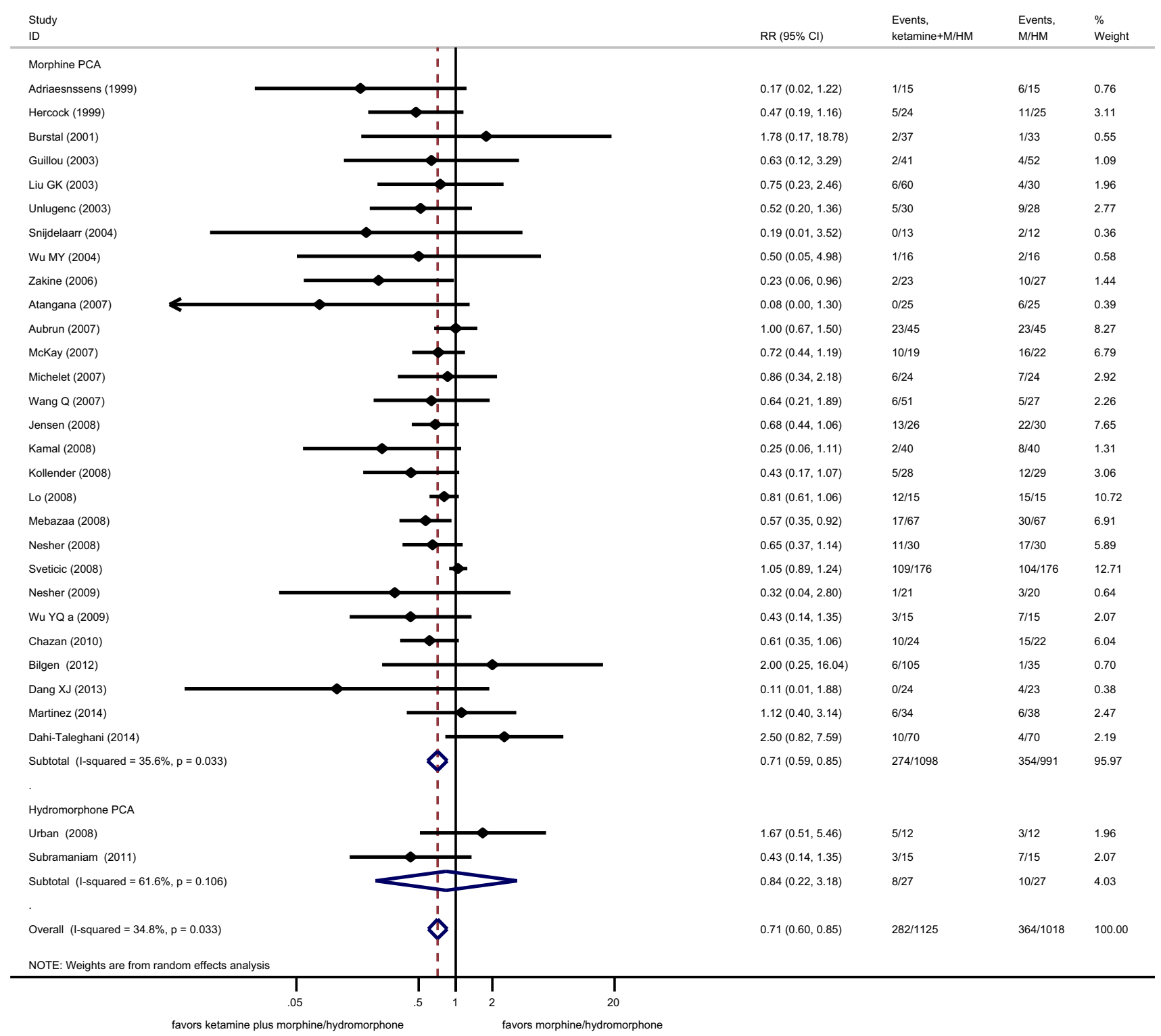

Fig. 5 Combination of ketamine and morphine/hydromorphone patient-controlled analgesia (PCA) $v s$ morphine/hydromorphone PCA: postoperative nausea and vomiting

evaluate all clinically relevant outcomes explored in this current meta-analysis. ${ }^{4,6}$

Besides the additional pain reduction and morphine sparing effect, adding ketamine to morphine PCA also reduced PONV by an absolute risk reduction of $8.9 \%(95 \%$ CI, 4.6 to 12.2), which equates to a NNT of 11 (95\% CI, 8 to 20) (GRADE: moderate confidence). No significant differences were found for other adverse events, including neuropsychiatric adverse events that have been attributed to ketamine at higher doses (GRADE: moderate confidence); however, very few trials reported on adverse events, and there remains a significant risk of underreporting of adverse events. Whether the reduction of morphine-related adverse events, e.g., PONV, is due to the decreased morphine consumption after adding ketamine remains uncertain. Nevertheless, this metaanalysis lends support for the relationship between reduced opioid leading to reduced $\mathrm{PONV}^{41,45}$ but without sufficient reports from the included studies regarding other opioid-related adverse events.

Since the complexity of drug administration increases when drugs are used in combination, these additional tradeoffs should be considered when deciding if this combination of drugs is worthy of the potentially small benefits, and the remaining unexplored risks, compared with morphine or hydromorphone PCA alone. 
Table 3 Subgroup analysis of effect of adding ketamine to morphine PCA and hydromorphone PCA

\begin{tabular}{|c|c|c|c|c|c|c|c|}
\hline Outcomes & Time point & Subgroups & $\begin{array}{l}\text { No. of } \\
\text { comparisons }\end{array}$ & $\begin{array}{l}\text { Sample } \\
\text { size }\end{array}$ & WMD & $95 \% \mathrm{CI}$ & $\begin{array}{l}\text { Interaction } P \\
\text { value }\end{array}$ \\
\hline \multirow[t]{8}{*}{ Pain score at rest } & \multirow[t]{2}{*}{$4-6 \mathrm{hr}$} & Morphine & 23 & 1,352 & -0.8 & -1.1 to -0.4 & \multirow[t]{2}{*}{0.10} \\
\hline & & Hydromorphone & 2 & 54 & -2.3 & -5.6 to 1.0 & \\
\hline & \multirow[t]{2}{*}{$12 \mathrm{hr}$} & Morphine & 19 & 1,063 & -0.8 & -1.3 to -0.4 & \multirow[t]{2}{*}{0.88} \\
\hline & & Hydromorphone & 1 & 30 & -0.6 & -2.7 to 1.5 & \\
\hline & \multirow[t]{2}{*}{$24 \mathrm{hr}$} & Morphine & 30 & 1,775 & -0.5 & -0.8 to -0.3 & \multirow[t]{2}{*}{0.26} \\
\hline & & Hydromorphone & 3 & 113 & -1.4 & -2.2 to -0.5 & \\
\hline & \multirow[t]{2}{*}{$48 \mathrm{hr}$} & Morphine & 22 & 1,692 & -0.4 & -0.6 to -0.2 & \multirow[t]{2}{*}{0.93} \\
\hline & & Hydromorphone & 2 & 54 & -0.4 & -1.7 to 0.9 & \\
\hline \multirow[t]{8}{*}{ Pain score during mobilization } & \multirow[t]{2}{*}{$4-6 \mathrm{hr}$} & Morphine & 6 & 720 & -0.1 & -0.9 to 0.7 & \multirow[t]{2}{*}{0.86} \\
\hline & & Hydromorphone & 1 & 30 & 0.2 & -2.1 to 2.5 & \\
\hline & \multirow[t]{2}{*}{$12 \mathrm{hr}$} & Morphine & 8 & 794 & -0.5 & -0.8 to -0.2 & \multirow[t]{2}{*}{0.61} \\
\hline & & Hydromorphone & 1 & 30 & 0.2 & -1.9 to 2.3 & \\
\hline & \multirow[t]{2}{*}{$24 \mathrm{hr}$} & Morphine & 13 & 1,090 & -0.4 & -0.5 to -0.2 & \multirow[t]{2}{*}{0.22} \\
\hline & & Hydromorphone & 2 & 54 & -1.4 & -3.3 to 0.6 & \\
\hline & \multirow[t]{2}{*}{$48 \mathrm{hr}$} & Morphine & 10 & 1,001 & -0.5 & -0.8 to -0.1 & \multirow[t]{2}{*}{0.82} \\
\hline & & Hydromorphone & 2 & 54 & -0.6 & -2.0 to 0.7 & \\
\hline \multirow{4}{*}{$\begin{array}{l}\text { Cumulative morphine } \\
\text { consumption }\end{array}$} & \multirow[t]{2}{*}{$24 \mathrm{hr}$} & Morphine & 27 & 1,769 & -4.9 & -7.1 to -2.7 & \multirow[t]{2}{*}{0.27} \\
\hline & & Hydromorphone & 3 & 113 & -27.5 & -63.9 to 8.9 & \\
\hline & \multirow[t]{2}{*}{$48 \mathrm{hr}$} & Morphine & 20 & 1,142 & -12.1 & -18.2 to -5.9 & \multirow[t]{2}{*}{0.12} \\
\hline & & Hydromorphone & 2 & 54 & -56.5 & $\begin{array}{l}-103.4 \text { to } \\
-9.6\end{array}$ & \\
\hline \multirow[t]{4}{*}{ Patient satisfaction } & \multirow[t]{2}{*}{$24 \mathrm{hr}$} & Morphine & 5 & 294 & -0.1 & -0.6 to 0.4 & \multirow[t]{2}{*}{0.14} \\
\hline & & Hydromorphone & 1 & 59 & 1.6 & 0.2 to 3.0 & \\
\hline & \multirow[t]{2}{*}{$48 \mathrm{hr}$} & Morphine & 3 & 187 & 0.05 & -1.3 to 1.3 & \multirow[t]{2}{*}{0.89} \\
\hline & & Hydromorphone & 1 & 30 & -0.3 & -2.4 to 1.9 & \\
\hline \multirow{2}{*}{$\begin{array}{l}\text { Postoperative nausea and } \\
\text { vomiting }\end{array}$} & \multirow{2}{*}{$\begin{array}{l}\text { Type of } \\
\text { opioid }\end{array}$} & Morphine & 28 & 2,089 & 0.71 & 0.59 to 0.85 & \multirow[t]{2}{*}{0.76} \\
\hline & & Hydromorphone & 2 & 54 & 0.84 & 0.22 to 3.18 & \\
\hline
\end{tabular}

$\mathrm{CI}=$ confidence interval $\mathrm{PCA}=$ patient-controlled analgesia $; \mathrm{WMD}=$ weighted mean difference

\section{Strengths and limitations}

This review is strengthened by the inclusion of comprehensive searches of six databases without limits by language or publication status. This resulted in identifying 22 RCTs not included in previous systematic reviews. ${ }^{2-6}$ We used all data available, made reasonable assumptions about unclear or missing data, and conducted sensitivity analyses that suggested our results are robust to these assumptions. We analyzed the effect of additional ketamine on pain both at rest and during mobilization and standardized the pain score measurements. We applied GRADE, a transparent method for rating confidence in estimates (quality of evidence) widely endorsed by the international systematic review and practice guideline community, ${ }^{11,12}$ to provide context for interpreting the findings.

There are some limitations to our systematic review. Substantial statistical heterogeneity was observed among pain outcomes, likely as a result of clinical heterogeneity among the patients (e.g., age, type of illness, type of surgery), and interventions (dose, route, duration of ketamine, ratio of ketamine vs morphine, anesthesia, postoperative analgesia, and other co-interventions), though subgroup analysis examining some of these variables failed to show clear relationships. The variability in results across studies was the primary reason for rating confidence in effects on pain as moderate rather than high. Also, we did not perform sensitivity analysis to address the impact of loss to followup, although the proportion of loss to follow-up ranged from 3-9\%. Meta-regression failed to detect an association between total dose of ketamine or ratio of ketamine-tomorphine and effect sizes; thus, the optimal dose or ratio of ketamine-to-opioid still remains unclear. Finally, this metaanalysis could not address whether adding ketamine to morphine or hydromorphone reduces chronic pain since the included studies did not evaluate longer-term outcomes. 
In this meta-analysis, most patients represented a low-risk population as indicated by low VAS scores in the control group, suggesting they were well controlled on morphine or hydromorphone PCA. Potentially, patients with higher VAS scores at baseline would be more likely to benefit from adjunctive ketamine; however, this meta-analysis did not provide sufficient data for us to test this hypothesis.

Significant differences were not detected for most of the opioid-related or ketamine-related adverse events, with the exception of PONV. The confidence intervals remain wide for some of these adverse events (e.g., respiratory depression, pruritus, urinary retention, diplopia, cardiovascular adverse effects), since only a few trials reported on these incidents. Therefore, the existing evidence base remains underpowered to rule out important differences that may exist for these underreported adverse events.

Implications for practice and summary

This meta-analysis of randomized trials provides objective evidence that adding ketamine to morphine or hydromorphone PCA provides a small improvement in postoperative analgesia while reducing morphine requirements in patients receiving morphine or hydromorphone PCA. Adjunctive ketamine also reduces PONV without a detected increase in the risk of neuropsychiatric effects. Nevertheless, the risk of adverse events was difficult to quantify since studies rarely reported on adverse events. Future research should explore the optimal ratio of ketamine-to-morphine and whether higher risk patients would reap more benefit (i.e., opioid-tolerant patients or patients with a high baseline pain score).

Acknowledgements We sincerely thank Brie McConnell and Jessica Moodie for the searches and article retrieval and Prof. Gordon Guyatt for support with methodology.

Conflicts of interest None declared.

Funding We thank the AMOSO Innovation Fund (Project \#INN 11008, Dr. J. Martin and Dr. D. Cheng) and the National Natural Science Foundation of China (Project \# 71073105, Dr. L. Wang). The funding organizations had no role in the design and conduct of the study, the collection, analysis, and interpretation of the data, or the preparation, review, or approval of the manuscript.

\section{References}

1. Niesters M, Martini C, Dahan A. Ketamine for chronic pain: risks and benefits. Br J Clin Pharmacol 2014; 77: 357-67.

2. Bell RF, Dahl JB, Moore RA, Kalso E. Perioperative ketamine for acute postoperative pain. Cochrane Database Syst Rev 2006; 1: CD004603.

3. Carstensen $M$, Moller AM. Adding ketamine to morphine for intravenous patient-controlled analgesia for acute postoperative pain: a qualitative review of randomized trials. $\mathrm{Br} \mathrm{J}$ Anaesth 2010; 104: 401-6.

4. Elia $N$, Tramer MR. Ketamine and postoperative pain-a quantitative systematic review of randomised trials. Pain 2005; 113: 61-70.

5. Laskowski K, Stirling A, McKay WP, Lim HJ. A systematic review of intravenous ketamine for postoperative analgesia. Can J Anesth 2011; 58: 911-23.

6. Subramaniam K, Subramaniam B, Steinbrook RA. Ketamine as adjuvant analgesic to opioids: a quantitative and qualitative systematic review. Anesth Analg 2004; 99: 482-95.

7. Moher D, Liberati A, Tetzlaff J, Altman DG, PRISMA Group. Preferred reporting items for systematic reviews and meta-analyses: the PRISMA statement. J Clin Epidemiol 2009; 62: 1006-12.

8. Schmid RL, Sandler AN, Katz, J. Use and efficacy of low-dose ketamine in the management of acute postoperative pain: a review of current techniques and outcomes. Pain 1999; 82: 111-25.

9. Higgins JP, Green S. Cochrane Handbook for Systematic Reviews of Interventions. The Cochrane Collaboration, 2011. Available from URL: www.cochrane-handbook.org (accessed July 2015)

10. Thorlund K, Walter SD, Johnston BC, Furukawa TA, Guyatt GH. Pooling health-related quality of life outcomes in metaanalysis-a tutorial and review of methods for enhancing interpretability. Res Synth Methods 2011; 2: 188-203.

11. Guyatt GH, Oxman AD, Vist GE, et al. GRADE: an emerging consensus on rating quality of evidence and strength of recommendations. BMJ 2008; 336: 924-6.

12. Guyatt $G$, Oxman AD, Akl EA, et al. GRADE guidelines: 1. Introduction-GRADE evidence profiles and summary of findings tables. J Clin Epidemiol 2011; 64: 383-94.

13. Guyatt GH, Oxman AD, Montori $V$, et al. GRADE guidelines: 5 . Rating the quality of evidence-publication bias. J Clin Epidemiol 2011; 64: 1277-82.

14. Guyatt GH, Oxman AD, Kunz R, et al. GRADE guidelines: 7 . Rating the quality of evidence-inconsistency. J Clin Epidemiol 2011; 64: 1294-302.

15. Guyatt GH, Oxman AD, Kunz R, et al. GRADE guidelines: 8 . Rating the quality of evidence-indirectness. J Clin Epidemiol 2011; 64: 1303-10.

16. Guyatt GH, Oxman AD, Santesso N, et al. GRADE guidelines: 12. Preparing summary of findings tables-binary outcomes. J Clin Epidemiol 2013; 66: 158-72.

17. Guyatt GH, Thorlund $K$, Oxman AD, et al. GRADE guidelines: 13. Preparing summary of findings tables and evidence profilescontinuous outcomes. J Clin Epidemiol 2013; 66: 173-83.

18. Adriaenssens $G$, Vermeyen KM, Hoffmann VL, Mertens E, Adriaensen $H F$. Postoperative analgesia with i.v. patientcontrolled morphine: effect of adding ketamine. Br J Anaesth 1999; 83: 393-6.

19. Atangana $R$, Ngowe Ngowe M, Binam F, Sosso MA. Morphine versus morphine-ketamine association in the management of post operative pain in thoracic surgery. Acta Anaesthesiol Belg 2007; 58: $125-7$.

20. Aubrun F, Gaillat C, Rosenthal D, et al. Effect of a low-dose ketamine regimen on pain, mood, cognitive function and memory after major gynaecological surgery: a randomized, double-blind, placebo-controlled trial. Eur J Anaesthesiol 2008; 25: 97-105.

21. Bilgen S, Koner O, Ture H, Menda F, Ficicioglu C, Aykac B. Effect of three different doses of ketamine prior to general anaesthesia on postoperative pain following caesarean delivery: a prospective randomized study. Minerva Anestesiol 2012; 78: 442-9.

22. Burstal R, Danjoux $G$, Hayes $C$, Lantry $G$. PCA ketamine and morphine after abdominal hysterectomy. Anaesth Intensive Care 2001; 29: 246-51. 
23. Chazan S, Buda I, Nesher N, Paz J, Weinbroum A. Low-dose ketamine via intravenous patient-controlled analgesia device after various transthoracic procedures improves analgesia and patient and family satisfaction. Pain Manag Nurs 2010; 11: 169-76.

24. Dahi-Taleghani M, Fazli B, Ghasemi M, Vosoughian $M$, Dabbagh A. Effect of intravenous patient controlled ketamine analgesiaon postoperative pain in opium abusers. Anesth Pain Med 2014; 4: e14129.

25. Grady MV, Mascha E, Sessler DI, Kurz A. The effect of perioperative intravenous lidocaine and ketamine on recovery after abdominal hysterectomy. Anesth Analg 2012; 115: 1078-84.

26. Guillou $N$, Tanguy $M$, Seguin P, Branger B, Campion JP, Malledant $Y$. The effects of small-dose ketamine on morphine consumption in surgical intensive care unit patients after major abdominal surgery. Anesth Analg 2003; 97: 843-7.

27. Hercock T, Gillham MJ, Sleigh J, Jones SF. The addition of ketamine to patient controlled morphine analgesia does not improve quality of analgesia after total abdominal hysterectomy. Acute Pain 1999; 2: 68-72.

28. Javery KB, Ussery $T W$, Steger $H G$, Colclough $G W$. Comparison of morphine and morphine with ketamine for postoperative analgesia. Can J Anaesth 1996; 43: 212-5.

29. Jensen LL, Handberg G, Helbo-Hansen HS, et al. No morphine sparing effect of ketamine added to morphine for patientcontrolled intravenous analgesia after uterine artery embolization. Acta Anaesthesiol Scand 2008; 52: 479-86.

30. Kamal HM. Ketamine as an adjuvant to morphine for patient controlled analgesia in morbidly obese patients. J Med Sci 2008; 8: 364-70.

31. Kollender Y, Bickels J, Stocki D, et al. Subanaesthetic ketamine spares postoperative morphine and controls pain better than standard morphine does alone in orthopaedic-oncological patients. Eur J Cancer 2008; 44: 954-62.

32. Lo A, Macpherson N, Spiwak $R$. Prospective randomized trial of patient-controlled analgesia with ketamine and morphine or morphine alone after hysterectomy. Can J Hosp Pharm 2008; 61: 334-9.

33. Martinez V, Cymerman A, Ben Ammar S, et al. The analgesic efficiency of combined pregabalin and ketamine for total hip arthroplasty: a randomised, double-blind, controlled study. Anaesthesia 2014; 69: 46-52.

34. McKay WP, Donais P. Bowel function after bowel surgery: morphine with ketamine or placebo; a randomized controlled trial pilot study. Acta Anaesthesiol Scand 2007; 51: 1166-71.

35. Michelet P, Guervilly $C$, Helaine A, et al. Adding ketamine to morphine for patient-controlled analgesia after thoracic surgery: influence on morphine consumption, respiratory function, and nocturnal desaturation. Br J Anaesth 2007; 99: 396-403.

36. Murdoch CJ, Crooks BA, Miller CD. Effect of the addition of ketamine to morphine in patient-controlled analgesia. Anaesthesia 2002; 57: 484-8.

37. Nesher N, Ekstein MP, Paz Y, Marouani N, Chazan S, Weinbroum AA. Morphine with adjuvant ketamine vs higher dose of morphine alone for immediate postthoracotomy analgesia. Chest 2009; 136: 245-52.

38. Nesher N, Serovian I, Marouani N, Chazan S, Weinbroum AA. Ketamine spares morphine consumption after transthoracic lung and heart surgery without adverse hemodynamic effects. Pharmacol Res 2008; 58: 38-44.

39. Nitta R, Goyagi T, Nishikawa T. Combination of oral clonidine and intravenous low-dose ketamine reduces the consumption of postoperative patient-controlled analgesia morphine after spine surgery. Acta Anaesthesiol Taiwan 2013; 51: 14-7.

40. Reeves $M$, Lindholm DE, Myles PS, Fletcher H, Hunt JO. Adding ketamine to morphine for patient-controlled analgesia after major abdominal surgery: a double-blinded, randomized controlled trial. Anesth Analg 2001; 93: 116-20.

41. Sami Mebazaa M, Mestiri T, Kaabi B, Ben Ammar MS. Clinical benefits related to the combination of ketamine with morphine for patient controlled analgesia after major abdominal surgery. Tunis Med 2008; 86: 435-40.

42. Snijdelaar DG, Cornelisse HB, Schmid RL, Katz J. A randomised, controlled study of peri-operative low dose $s(+)$-ketamine in combination with postoperative patient-controlled $s(+)$-ketamine and morphine after radical prostatectomy. Anaesthesia 2004; 59: 222-8.

43. Sveticic $G$, Farzanegan $F$, Zmoos $P$, Zmoos $S$, Eichenberger $U$, Curatolo $M$. Is the combination of morphine with ketamine better than morphine alone for postoperative intravenous patientcontrolled analgesia? Anesth Analg 2008; 106: 287-93.

44. Unlugenc H, Ozalevli M, Guler T, Isik G. Postoperative pain management with intravenous patient-controlled morphine: comparison of the effect of adding magnesium or ketamine. Eur J Anaesthesiol 2003; 20: 416-21.

45. Zakine J, Samarcq D, Lorne E, et al. Postoperative ketamine administration decreases morphine consumption in major abdominal surgery: a prospective, randomized, double-blind, controlled study. Anesth Analg 2008; 106: 1856-61.

46. Barreveld AM, Correll DJ, Liu X, et al. Ketamine decreases postoperative pain scores in patients taking opioids for chronic pain: results of a prospective, randomized, double-blind study. Pain Medicine 2013; 14: 925-34.

47. Subramaniam K, Akhouri V, Glazer PA, et al. Intra- and postoperative very low dose intravenous ketamine infusion does not increase pain relief after major spine surgery in patients with preoperative narcotic analgesic intake. Pain Med 2011; 12: 127683.

48. Urban MK, Ya Deau JT, Wukovits B, Lipnitsky JY. Ketamine as an adjunct to postoperative pain management in opioid tolerant patients after spinal fusions: a prospective randomized trial. HSS J 2008; 4: 62-5.

49. Dang XJ, Su SY, Sun LL, He LH, Wu JR. Analgesic effect of ketamine adding to morphine in patient-controlled analgesia for patients after surgery for femur fracture (Chinese). Guang Dong Yi Xue 2013; 34: 608-11.

50. Liu GK, Huang YG, Luo AL, Ren HZ, Zhang YF. Patientcontrolled intravenous morphine and ketamine for postoperative analgesia (Chinese). Zhong Hua Ma Zui Xue Za Zhi 2003; 23 : 416-8.

51. Wang $Q$, Wang ZC, Wang $B G$. Continuous intravenous infusion of low dose of ketamine combined with morphine used for postoperative analgesia in patients with cervical spinal cord injury (Chinese). Zhong Guo Kang Fu Li Lun Yu Shi Jian 2007; 13: 86-8.

52. Wu MY, Xing $C Y$, Ren YC, Y. DL, Liu B, Jiang $H$. Effects of perioperative low dose ketamine (Chinese). Di Si Jun Yi Da Xue Xue Bao 2004; 25: 2161.

53. $W u Y Q, L i H$, Xiong JC, et al. Effects of patient-controlled analgesia with small dose ketamine combined with morphine and the influence thereof on plasma $\beta$-endorphin level in patients after radical operation for esophageal carcinoma. Zhonghua Yi Xue Za Zhi 2009; 89: 314-7. 